\title{
Hubungan obesitas dengan tekanan darah dan aktivitas fisik pada remaja di Kota Bitung
}

\author{
${ }^{1}$ Deviwanti Batara \\ ${ }^{2}$ Widdhi Bodhi \\ ${ }^{2}$ Billy J. Kepel
}

\author{
${ }^{1}$ Kandidat Skripsi Fakultas Kedokteran Sam Ratulangi Manado \\ ${ }^{2}$ Bagian Kimia Fakultas Kedokteran Universitas Sam Ratulangi Manado \\ Email: deviwantibatara@gmail.com
}

\begin{abstract}
Obesity is one of the global health problem which is often found. Indonesia is a developing country with high incident of obesity. Adolescents are the age group with high levels of obesity risk. The increasing of obesity followed by increasing co-morbidity the potential to be disease in a later time. Obesity increasing the risk of high blood pressure. Hypertension in adolescents already many found. Hypertension in adolescents is problem because it can be continued in adults. one important factor which play a role in obesity is physical activity. Objective: This research to determine the relationship of obesity with blood pressure and physical activity in adolescents in Bitung. Methodology: This study was observational analytic cross sectional design. Results: There were 60 subjekts as the subject of study that meets the inclusions kriteria which have been measured. Consisted of 21 boys and 39 girls. Of 60 obese adolescents are 34 adolescents with high blood pressure, 26 adolescent with normal blood pressure, 52 adolescent with moderate physical activity, 8 adolescents with low physical activity, there is no a significant relationship with blood pressure (Chi Square Test $p=0,120$ ), and there is no a significant relationship with physical activity (Chi Square Test: $p=0,486$. Conclusion: There is no a relationship between obesity with blood pressure and physical activity in adolescents in Bitung.
\end{abstract}

Keywords: obesity, blood pressure and physical activity.

\begin{abstract}
Abstrak: Obesitas merupakan salah satu masalah kesehatan dunia yang semakin sering ditemukan. Indonesia merupakan salah satu negara berkembang dengan tingkat obesitas yang tinggi. Remaja merupakan kelompok umur dengan tingkat risiko obesitas yang tinggi. Peningkatan obesitas disertai dengan peningkatan ko-morbiditas yang berpotensi menjadi penyakit degeneratif di kemudian hari. Obesitas meningkatkan resiko terjadinya penyakit tekanan darah tinggi. Hipertensi pada remaja sudah banyak ditemukan. Hipertensi pada remaja merupakan suatu masalah karena dapat berlanjut hingga usia dewasa. Salah satu faktor penting yang berperan pada obesitas adalah aktivitas fisik. Obesitas. Tujuan: Untuk mengetahui hubungan obesitas dengan tekanan darah dan aktivitas fisik pada remaja di kota Bitung. Metode: Penelitian ini merupakan penelitian observasional analitik. Hasil: Terdapat 60 subjek yang memenuhi kriteria inklusi yang telah diukur. Terdiri dari 39 perempuan dan 21 laki-laki dan 39 perempuan. Dari 60 remaja obes tersebut, 34 remaja dengan tekanan darah tinggi, 26 remaja dengan tekanan darah normal, 52 dengan aktivitas fisik sedang, 8 dengan aktivitas fisik rendah, tidak terdapat hubungan bermakna dengan tekanan darah (Uji Chi Square : $\mathrm{p}=0,120$ ), dan dengan aktivitas fisik (Uji Chi Square : $\mathrm{p}=0,486$ ). Simpulan: Tidak terdapat hubungan antara obesitas dengan tekanan darah dan aktivitas fisik pada remaja di kota Bitung.
\end{abstract}

Kata kunci: obesitas, tekanan darah, aktivitas fisik 
Obesitas merupakan salah satu masalah kesehatan dunia yang semakin sering ditemukan. Di Amerika Serikat obesitas merupakan masalah yang serius karena angka kejadian obesitas semakin meningkat setiap tahunnya. ${ }^{1}$ Peningkatan prevelensi obesitas tidak hanya terjadi di negara maju tapi juga di negara-negara berkembang. Indonesia merupakan salah satu negara berkembang dengan tingkat obesitas yang tinggi. Remaja merupakan kelompok umur dengan tingkat risiko obesitas yang tinggi. Riskesdas 2013, diketahui bahwa obesitas pada kelompok umur 13-15 tahun di Indonesia sebesar $2,5 \%{ }^{2}$ Berdasarkan data tersebut, Indonesia perlu melakukan penanganan secepatnya untuk mengatasi masalah obesitas khususnya pada remaja. ${ }^{3}$

Peningkatan obesitas disertai dengan peningkatan ko-morbiditas yang berpotensi menjadi penyakit degeneratif di kemudian hari misalnya penyakit jantung koroner, DM tipe 2 dan hipertensi. ${ }^{4}$ Obesitas meningkatkan resiko terjadinya penyakit tekanan darah tinggi. Tekanan darah yang normal yaitu 120/80 mmHg namun dalam kondisi tertentu tekanan darah bisa melebihi batas normal yang dikenal sebagai hipertensi. ${ }^{5}$

Hipertensi dulunya lebih banyak dijumpai pada dewasa dan jarang pada remaja tapi sekarang ini hipertensi pada remaja sudah banyak ditemukan. ${ }^{6}$ Hipertensi pada remaja merupakan suatu masalah karena dapat berlanjut hingga usia dewasa dengan resiko morbiditas dan mortalitas yang tinggi. ${ }^{7}$ Menurut penelitian sebelumnya, di Indonesia hipertensi pada remaja sekitar $3,11 \%$ sampai $4,6 \%{ }^{8}$ Hipertensi pada remaja masih sulit didefinisikan karena nilai tekanan darah normal bervariasi pada berbagai usia. Menururt kriteria diagnosis IDF batasan hipertensi pada remaja yaitu, bila tekanan darah systolic $\geq 130$ dan diastolic $\geq 85$ mmHg.

Hubungan obesitas dan tekanan darah dimana pada remaja yang obes memiliki tekanan darah lebih tinggi dibandingkan dengan anak non obes. Adanya interaksi antara retensi sodium, aktivasi sistem saraf simpatis dan selektif insulin resistensi merupakan hipotesis yang paling mungkin menjelaskan terjadinya hipertensi pada obesitas. Selektif resistensi insulin pada obesitas menimbulkan hiperinsulinemia yang berefek pada gangguan fungsi vaskuler, gangguan transport ion, retensi sodium, dan peningkatan aktivitas saraf simpatis termasuk peningkatan denyut jantung dan tekanan darah., ${ }^{9,10}$

Salah satu faktor penting yang berperan pada obesitas adalah aktivitas fisik. Obesitas bukan hanya terkait masalah banyaknya mengonsumsi makanan tapi juga kurangnya aktivitas fisik. Seiring dengan perkembangan zaman terjadi berbagai perubahan gaya hidup, terutama pada aktivitas fisik. Olahraga, jalan kaki, permainan fisik atau aktivitas fisik yang lainnya semakin jarang dilakukan. Kebanyakan sekolah memberikan jadwal olahraga hanya satu kali dalam seminggu dan sisanya diisi dengan belajar dalam ruangan. Ditambah lagi remaja sekarang ini lebih banyak menghabiskan waktu mereka dengan duduk sambil bermain gadjet, nongkrong sambil makan dengan temanteman sebayanya, nonton TV, les atau bimbel yang membuat mereka untuk duduk lebih lama dan juga kebanyakan dari mereka sekarang ini untuk berangkat maupun pulang sekolah diantar dan dijemput orang tua memakai kendaraan pribadi atau menggunakan kendaraan umum. $^{11}$

Sulawesi Utara termasuk salah satu kota di Indonesia dengan prevelensi obesitas yang tinggi. Kebiasaan masyarakat makan dengan porsi banyak dengan beragam makanan yang kebanyakan mengandung kalori dan lemak yang cukup tinggi sehingga kejadian obesitas semakin meningkat. Berdasarkan beberapa penelitian yang dilakukan sebelumnya, tahun 2005 remaja yang mengalami obesitas di kota Manado sebesar 9,88\%. ${ }^{12}$

Berdasarkan latar belakang diatas peneliti tertarik untuk melakukan penelitian mengenai hubungan kejadian obesitas dengan tekanan darah dan aktivitas fisik pada remaja Sekolah Menengah Atas 
khususnya di kota Bitung.

\section{METODE PENELITIAN}

Penelitian ini menggunakan penelitian observasional analitik dengan rancangan potong lintang.

Populasi penelitian ini adalah Semua remaja obes di Bitung yang berusia 13 sampai 18 tahun.

Sampel penelitian yaitu siswa-siswi obes yang diambil dari siswa-siswi SMA Negeri 1, SMA Negeri 2, SMA Kristen Tumou Tou Girian, SMA Katolik Don Bosco yang terletak di Kota Bitung dengan kriteria yaitu Siswa yang berusia 13 samapi 18 tahun, sehat, terdaftar dan aktif mengikuti kegiatan di sekolah serta bersedia menandatangani surat persetujuan untuk dijadikan sampel. Siswa-siswi SMA yang sebelumnya didiagnosis dengan obesitas .

\section{HASIL PENELITIAN}

Penelitian ini dilakukan pada remaja yang berada di kota Bitung, dan yang menjadi sumber penelitiannya adalah SMA Negeri 1, SMA Negeri 2, SMA Kristen Tumou Tou Girian, SMA Katolik Don Bosco yang terletak di Kota Bitung. Penelitian ini melibatkan 966 siswa, kemudian dilakukan pengukuran lingkar pinggang dan didapatkan 220 siswa obesitas. Kemudian berdasarkan kriteria inklusi terdapat 60 siswa obesitas yang terdiri dari 21 laki-laki dan 39 perempuan untuk dijadikan sampel.

\section{Karakteristik Subjek Penelitian}

\section{Jenis Kelamin}

Sebagian besar subjek berjenis kelamin perempuan yaitu sebesar 65\% (39 orang) laki-laki 35\% (21 orang).

\section{Tempat Tinggal}

Pada kategori tempat tinggal didapatkan $100 \%$ subjek tinggal dengan orang tua.

\section{Pekerjaan Orang Tua}

a. Pekerjaan Ayah

Sebagian besar subjek ayahnya bekerja sebagai wiraswasta yaitu sebesar 22 orang (36,7\%) dan yang paling sedikit bekerja sebagai buruh sebesar 2 orang (3,3\%). b. Pekerjaan Ibu

Sebagian besar subjek ibunya tidak bekerja yaitu sebanyak 39 orang (65,\%), dan yang paling sedikit bekerja sebagai wiraswasta sebesar 2 orang $(3,4 \%)$.

\section{Pendidikan Orang Tua}

a. Pendidikan Ayah

Kategori tingkat pendidikan terbanyak subjek pendidikan terakhir ayahnya adalah SLTA sebanyak 41 orang $(68,3)$, dan yang paling sedikit adalah Sarjana yaitu 1 orang $(1,7 \%)$.

\section{b. Pendidikan Ibu}

Kategori tingkat pendidikan terbanyak subjek yang pendidikan terakhir ibunya adalah SLTA sebesar 39 orang (65,0\%), dan yang paling sediki adalah strata dua yaitu 1 orang (1,7\%).

\section{Analisis Unvariat}

\section{Tekanan Darah}

Tabel 1. Distribusi Tekanan Darah

\begin{tabular}{ccc}
\hline Tekanan Darah & $\mathrm{n}$ & $\%$ \\
\hline Rendah & 8 & 13,3 \\
Sedang & 52 & 86,7 \\
\hline Total & 60 & 100
\end{tabular}

Tabel 1 menunjukkan subjek yang termasuk dalam kategori tekanan darah tinggi sebanyak 34 orang (56,7\%), sedangkan subjek yang tekanan darahnya normal sebanyak 26 orang (43,3\%).

\section{Aktivitas Fisik}

Tabel 2. DistribusiAktivitas Fisik

\begin{tabular}{ccc}
\hline Aktivitas Fisik & $\mathrm{N}$ & $\%$ \\
\hline Rendah & 8 & 13,3 \\
Sedang & 52 & 86,7 \\
\hline Total & 60 & 100 \\
\hline
\end{tabular}

Tabel 2 menunjukkan subjek yang termasuk dalam kategori aktivitas fisik sedang sebanyak 52 orang (86,7\%) dan subjek yang aktivitas fisiknya rendah sebanyak 8 orang (13,3\%). Sedangkan subjek dengan kategori aktivitas yang berat tidak ada. 


\section{Aktivitas Fisik menurut Jenis Kelamin}

Tabel 3. Distribusi berdasarkan aktivitas fisik meurut Jenis Kelamin

\begin{tabular}{|c|c|c|c|}
\hline \multirow[t]{2}{*}{ Jenis Kelamin } & \multicolumn{2}{|c|}{ Aktivitas Fisik } & \multirow{2}{*}{ Total } \\
\hline & $\begin{array}{c}\text { Ringan } \\
n\end{array}$ & $\begin{array}{c}\text { Sedang } \\
\mathrm{N}\end{array}$ & \\
\hline Laki-Laki & 3 & 18 & 21 \\
\hline Perempuan & 5 & 35 & 39 \\
\hline Total & 8 & 52 & 60 \\
\hline
\end{tabular}

Berdasarkan tabel 3 dari 39 orang subjek perempuan sebanyak 35 orang dengan aktivitas fisik sedang dan 5 orang dengan aktivitas fisik ringan. Sedangkan dari 21 orang subjek laki-laki, sebanyak 18 orang dengan aktivitas fisik sedang dan 3 orang dengan akivitas fisik ringan.

\section{Tekanan Darah menurut Jenis Kelamin}

Tabel 4. Distribusi Tekanan Darah menurut Jenis Kelamin

\begin{tabular}{cccc}
\hline Jenis Kelamin & \multicolumn{2}{c}{ Tekanan Darah } & Total \\
\cline { 2 - 3 } & $\begin{array}{c}\text { Hipertensi } \\
\mathrm{n}\end{array}$ & $\begin{array}{c}\text { Normal } \\
\mathrm{n}\end{array}$ & \\
\hline Laki-Laki & 18 & 3 & 21 \\
Perempuan & 16 & 23 & 39 \\
\hline Total & 34 & 26 & 60 \\
\hline
\end{tabular}

Berdasarkan tabel 4 dari 39 orang subjek perempuan sebanyak 23 orang dengan tekanan darah normal dan 16 orang dengan hipertensi. Sedangkan dari 21 subjek laki-laki, sebanyak 18 orang dengan hipertensi dan 3 orang dengan tekanan darah normal.

\section{Analisis Bivariat}

1. Hubungan Obesitas dengan Tekanan Darah

Berdasarkan Tabel 5 dapat diketahui bahwa subjek dengan obesitas terdapat 31 orang dengan hipertensi dan 26 orang tekanan darah normal. Sedangkan untuk subjek dengan berat badan normal terdapat 3 orang dengan tekanan darah normal.
Hasil uji statistik menggunakan uji Chi Square diperoleh nilai $p$ sebesar 0,120 yakni $>0,05$. Berarti $\mathrm{H}_{0}$ diterima atau tidak terdapat hubungan antara obesitas dengan tekanan darah.

Tabel 5. Hubungan Obesitas dengan Tekanan Darah

\begin{tabular}{ccccc}
\hline Status & \multicolumn{2}{c}{ Tekanan Darah } & Total & $P$ \\
\cline { 2 - 3 } Gizi & Hipertensi & Normal & & \\
& $\mathrm{n}$ & $\mathrm{n}$ & & \\
Obesitas & 31 & 26 & 57 & 0,120 \\
Normal & 3 & 0 & 3 & \\
Total & 34 & 26 & 60 & \\
\hline
\end{tabular}

\section{Hubungan Obesitas dengan Aktivitas Fisik}

Tabel 6. Hubungan Obesitas dengan Aktivitas Fisik

\begin{tabular}{|c|c|c|c|c|}
\hline \multirow[t]{2}{*}{ Status Gizi } & \multicolumn{2}{|c|}{ Aktifitas Fisik } & \multirow[t]{2}{*}{ Total } & \multirow[t]{2}{*}{$P$} \\
\hline & $\begin{array}{c}\text { Ringan } \\
n\end{array}$ & $\begin{array}{c}\text { Sedang } \\
n\end{array}$ & & \\
\hline Obesitas & 8 & 49 & 57 & 0,486 \\
\hline Normal & & 3 & 3 & \\
\hline Total & 34 & 26 & 60 & \\
\hline
\end{tabular}

Berdasarkan Tabel 6 diatas, dapat diketahui bahwa dari 57 subjek dengan obesitas terdapat 49 subjek dengan aktifitas fisik sedang, 8 subjek dengan aktivitas ringan dan tidak ada yang beraktivitas berat. Sedangkan dari 3 orang subjek dengan status gizi normal terdapat 3 orang dengan aktivitas sedang dan tidak ada yang beraktivitas ringan ataupun berat. Hasil uji statistik menggunakan uji Chi Square diperoleh nilai $p$ sebesar 0,486 yakni > 0,05 . Berarti $\mathrm{H}_{0}$ diterima atau tidak terdapat hubungan antara obesitas dengan aktivitas fisik.

\section{BAHASAN}

Berdasarkan hasil penelitian dapat diketahui bahwa hasil uji statistik menggunakan uji Chi Square diperoleh nilai $p$ sebesar 0,120 yakni $>0,05$. Berarti $\mathrm{H}_{\mathrm{o}}$ diterima atau tidak terdapat hubungan antara obesitas dengan tekanan darah. Hasil 
penelitian ini berbeda dengan hasil penelitian Verma et al yang menyatakan terdapat hubungan antara status gizi (dalam hal ini obesitas) dan tekanan darah (tekanan darah tinggi/hipertensi) pada siswa sekolah berusia 5-15 tahun di kota Punjab, India.

Perbedaan hasil penelitian ini dapat disebabkan oleh proses terjadinya hipertensi yang bersifat multifaktorial dan obesitas merupakan salah satu penyebab dari hipertensi. Berdasarkan hasil penelitian Diana tahun 2015 didapatkan penderita obesitas mempunyai resiko mengalami hipertensi lebih besar dibandingkan responden yang memiliki berat badan ideal atau normal. ${ }^{13}$

Hubungan antara obesitas dan hipertensi telah lama diketahui namun mekanisme bagaimana terjadinya hipertensi akibat obesitas hingga saat ini belum jelas. Sebagian peneliti menitikberatkan patofisiologi tersebut pada tiga hal utama yaitu adanya gangguan sistem autonom, resistensi insulin serta abnormalitas struktur dan fungsi pembuluh darah. Patogenesis obesitas sehingga mengakibatkan suatu hipertensi merupakan hal yang kompleks karena penyababnya multifaktor dan saling berhubungan. Leptin, asam lemak babas dan insulin serta obstructive sleep apnea yang meningkat pada anak obes akan menyebabkan konstriksi dan aktifitas sistem saraf simpatis. Resistensi insulin dan disfungsional endothelial juga menyebabkan vasokonstriksi. Peningkatan aktifitas saraf simpatis ginjal, resistensi insulin dan hiperaktifitas sistem renin angiotensi menjadikan reabsorbsi natrium pada ginjal meninggi. Semua faktor diatas akan mengakibatkan terjadinya hipertensi. $^{13,14}$

Berdasarkan hasil penelitian dapat diketahui bahwa hasil uji statistik menggunakan Chi Square diperoleh nilai $p$ sebesar 0,486 yakni > 0,05. Berarti $\mathrm{H}_{\mathrm{o}}$ diterima atau tidak terdapat hubungan antara obesitas dengan aktivitas fisik. Hasil penelitian ini berbeda dengan hasil penelitian Sudikno dkk tahun 2010 yang menunjukkan bahwa aktivitas fisik kurang memiliki risiko untuk menderita obesitas. Perbedaan hasil penelitian ini dapat disebabkan oleh mekanisme proses terjadinya obesitas. Proses terjadinya obesitas bukan hanya dipengaruhi oleh aktivitas fisik, namun pola makan dan genetik juga dapat mempengaruhi terjadinya obesitas. ${ }^{15-17}$ Berdasarkan hasil penelitian dapat diketahui bahwa siswa yang aktivitasnya sedang sebanyak 52 orang $(86,7 \%)$ dan siswa yang aktivitas fisiknya rendah sebanyak 8 orang (13,3\%). Sedangkan siswa dengan kategori aktivitas yang berat tidak ada. ${ }^{18}$

\section{SIMPULAN}

Dari penelitian yang dilakukan pada remaja di kota Bitung yaitu pada siswa SMA Negeri 1, SMA Negeri 2, SMA Kristen Tumou Tou Girian, SMA Katolik Don Bosco, SMK Negeri 1, SMK Negeri 2, maka dapat ditarik kesimpula adalah tidak terdapat hubungan antara obesitas dengan tekanan darah (uji Chi Square diperoleh nilai $p$ sebesar 0,120 yakni $>0,05$ ) dan aktivitas fisik (nilai $p$ sebesar 0,486 yakni $>$ $0,05)$

\section{SARAN}

1. Bagi remaja: Mengatur pola makan sehari-hari dan memperbanyak aktivitas fisik, terutama untuk siswa obes.

2. Bagi orang tua: Membantu anak dalam mengatur pola makan dan mengajarkan anak mengikuti pola hidup sehat.

3. Bagi Dinas Pendidikan, Pemuda dan Olahraga: Melakukan kerja sama dengan pihak sekolah untuk menyelenggarakan kegiatan-kegiatan yang meningkatkan pengetahuan remaja tentang kesehatan serta melakukan penyuluhan tentang factor resiko obesitas di sekolahsekolah.

4. Sebaiknya dilakukan penelitian yang lebih lanjut dengan menggunakan populasi yang lebih banyak agar hasil lebih jelas.

\section{DAFTAR PUSTAKA}

1. Sherwood, Lauralee. Fisiologi Manusia. Edisi ke-6. Jakarta: EGC; 2011. h. 
708

2. Riset Kesehatan Dasar. 2013. Laporan Nasional Riset Kesehatan Dasar (Riskesdas) 2013. Badan Penelitian Dan Pengembangan Kesehatan Depkes RI, Jakarta.

3. Tooy R, Manampiring A, Fatimawali. Gambaran Tekanan Darah pada Remaja Obes di Kabupaten Minahasa. e-Biomedik (eBM). 2013;1:951-5

4. Lumoindong A, Umboh A, Masloman N. Hubungan Obesitas dengan Profil Tekanan Darah pada Anak Usia 1012 tahun di kota Manado. e-biomedik. 2013;1:147-53.

5. Gunawan L. Hipertensi Tekanan Darah Tinggi. Yogyakarta:Kanisius , 2001;p.7.

6. Lumbantobing SM. Tekanan Darah Tinggi. Jakarta: Balai Penerbit FKUI, 2008;p.3.

7. Update on the 1987 Task Force Report on High Blood Pressure in Children and Adolescents. Pediatr 1996; 98:64958.

8. Saing J. Hipertensi pada remaja. Sari Pediatri. 2005; 6: 159.

9. Saing HS. Hipertensi Pada Remaja. Sari Pediatri. 2005;6:159-65.

10.Subardja D. obesitas Primer pada Anak : diagnosis, pathogenesis, dan patofisiologi. Edisi ke-1. Bandung: Kiblat;2004.
11. Mujur Andriardus. Hubungan antara Pola Makan dan Aktivitas Fisik dengan Kejadian Berat Badan Lebih pada Remaja. 2011 [diakses 18 September 2015]. Diunduh dari: http://core.ac.uk/download/pdf/11731 785.pdf

12.Kussoy karina, Fatimawali, Kepel Billy. Prevelensi Obesitas pada Remaja di Kabupaten Minahasa. e-Biomedik (eBM). 2013;1:982-5

13.Soetjningsih. Tumbuh Kembang Anak. Edisi ke-2. Jakarta : EGC; 2013. p. 611

14.Shen et al. Waist Circumference Correlates With Metabolic Syndrom Indicators Better Than Percentage Fat. Journal of Obesity, 2006; 14(1) p. 727-36.

15.Sudikno, Herdayati M, Bersal. Hubungan Aktifitas fisik Dengan Kejadian Obesitas Pada Orang Dewasa di Indonesia. Analisis Data

16.Iksan AN. Gambaran Profil Lipid Pada Siswa Obese di SMP Negeri 1 Manado. Jurnal e-Biomedik (eBM). 2015; 3(1) p. 72-9.

17.Fukuda S, Takeshita T. Obesity and Lifestyle. Asian Medical Journal. 2001;44(1) p. 97-102

18.Lumoindong A. Hubungan Obesitas Dengan Profil Tekanan Darah Pada Anak Usia 10-12 Tahun di Kota Manado. Jurnal e-Biomedik (eBM). 2013; 1(1) p. 147-53. 